\title{
Molecular Targets of Curcumin and Future Therapeutic Role in Leukemia
}

\author{
Sabika Rafiq1, Muhammad Hassan Raza ${ }^{2}$, Mehwish Younas', Fariha Naeem1', Romisha Adeeb1, \\ Javed Iqbal1, Pervez Anwar'1, Umara Sajid', Hafiza Muniba Manzoor ${ }^{3}$ \\ ${ }^{1}$ Department of Biotechnology, University of Gujrat Sialkot Subcampus, Sialkot, Pakistan \\ ${ }^{2}$ Department of Biotechnology \& Bioinformatics, International Islamic University, Islamabad, Pakistan \\ ${ }^{3}$ Department of Biotechnology, University of Health Sciences Lahore, Lahore, Pakistan \\ Email: sabikarafiq786@gmail.com
}

How to cite this paper: Rafiq, S., Raza, M.H., Younas, M., Naeem, F., Adeeb, R., Iqbal, J., Anwar, P., Sajid, U. and Manzoor, H.M. (2018) Molecular Targets of Curcumin and Future Therapeutic Role in Leukemia. Journal of Biosciences and Medicines, 6, 33-50.

https://doi.org/10.4236/jbm.2018.64003

Received: February 13, 2018

Accepted: April 20, 2018

Published: April 23, 2018

Copyright $\odot 2018$ by authors and Scientific Research Publishing Inc. This work is licensed under the Creative Commons Attribution International License (CC BY 4.0).

http://creativecommons.org/licenses/by/4.0/

\begin{abstract}
Leukemia is a most prevalent type of cancer around the globe. Due to major side effects of Chemotherapy and radiotherapy, scientists worked to explore the alternative source to treat leukemia. An alternative source for the treatment of leukemia existed in the form of curcumin, a natural phenolic compound extracted from curcuma longa plant. It exhibited anticancer properties reducing the tumor load via apoptosis and cell cycle arrested in various cancer cell lines and controlled tumor proliferation by blocking tumor inducing gene such as FLT3, Akt gene, ROS and NF- $\kappa$ B inhibition. At molecular level, curcumin plays a key therapeutic role in protection of normal cells by up regulation of NRF-2 that induces production of cellular antioxidants. It regulates various signaling pathways including NF-KB, JAK/STAT, PI3K/AKT and JNK pathways, thereby affecting cancer initiation, progression, and metastasis. This review described the potential of curcumin for treatment of leukemia; it affects different signaling cascades and their regulation. This study provides a preclinical foundation for future usage of curcumin in the treatment of cancer.
\end{abstract}

\section{Keywords}

Curcumin, Antioxidant, Signaling Pathways, Apoptosis, Therapeutic Potential, Leukemic Load

\section{Introduction}

Leukemia is a malignant disease of blood cells which arises due to mutations in growth promoting genes. Due to this abnormality, immature blood cells formed in bone marrow. The healthy blood cells die and are replaced with abnormal BCs, which lead to bone marrow failure, ultimately leading to death [1]. There are 
four main types of leukemia; acute myeloid leukemia (AML), acute lymphocytic leukemia (ALL), chronic myeloid leukemia (CML), chronic lymphocytic leukemia (CLL) (Table 1 [2] [3] [4] [5]). AML is a cancer of myeloid line of WBCs and affects people with age ranging from 15 to 70 years. It is caused due to chromosomal abnormalities, especially mutual alteration recognized in myelogenous leukemia in various genes such as RAS, FLT3, protein tyrosine, and P53 [6]. If it continues to develop in bone marrow cells, it damages myeloid cells and causes leukemic blasts in bone marrow and blood [7]. Meanwhile, CML is not a genetic disease; rather it is caused by aberration of different genes as there is interchange of DNA among long arms of two different chromosomes 9 and 22 leading expression of BCR-ABL gene; ultimately leading to CML [8]. Tyrosine kinase protein reduces amount of blood cells leading to anemia in CML patients [9]. ALL is a type of leukemia that mainly affects bone marrow. Some diseased conditions associated with ALL include anemia, lymphadenopathy, hepatomegaly and splenomegaly [10]. CLL is caused by defective immune system leading to increase in chances of infectious disease and malignancy is increased. Hypogammaglobulinemia is frequently present in immunocompromised patients [11]. It results from disruption of TP53 due to which CLL leukemic cells assemble in lymphoid tissues, blood and bone marrow [12]. These subtypes of leukemia are fatal when untreated leading to inhibition of hematopoiesis, anemia, granulocytopenia and their general symptoms include fatigue, weakness, pallor, susceptibility to infections and increased bleeding tendency [13].

Leukemia is one of the leading types of cancer across the globe. In 2014, data collected from United States revealed that total number of leukemia patients was 52,380 in which 30,100 patients were male while 22,280 were females. The number of deaths was as high as 24,090 in which 14,040 were females and 10,050 were males [14]. Similarly, in Australia number of cases diagnosed in 2017 was

Table 1. Different types of Leukemia and their attributes.

\begin{tabular}{|c|c|c|c|c|c|c|}
\hline Types & Cell involved & Cytology & Symptoms & Statistics & Prevalence & Ref. \\
\hline AML & $\begin{array}{c}\text { Immature } \\
\text { myeloid WBCs }\end{array}$ & $\begin{array}{c}\text { Oncogene } \\
\text { mutations, single } \\
\text { myeloblast } \\
\text { mutation, } \\
\text { Cytogenetic } \\
\text { abnormalities }\end{array}$ & $\begin{array}{l}\text { Anemia, } \\
\text { spontaneous } \\
\text { bleeding }\end{array}$ & $\begin{array}{l}\text { Both adults } \\
\text { and children }\end{array}$ & $80 \%$ & [2] \\
\hline CML & $\begin{array}{l}\text { Myeloid } \\
\text { stem cells }\end{array}$ & $\begin{array}{l}\text { Chromosomal } \\
\text { translocation, } \\
\text { granulocytes }\end{array}$ & $\begin{array}{l}\text { Anemia, low } \\
\text { platelet count, } \\
\text { enlarged spleen }\end{array}$ & $\begin{array}{l}\text { Rare in } \\
\text { children }\end{array}$ & $90 \%$ & [3] \\
\hline ALL & $\begin{array}{c}\text { Immature } \mathrm{B} \text { or } \mathrm{T} \\
\text { cell and } \\
\text { macrophages }\end{array}$ & $\begin{array}{l}\text { Chromosomal } \\
\text { aberration }\end{array}$ & $\begin{array}{l}\text { Disturb marrow } \\
\text { function }\end{array}$ & $\begin{array}{l}\text { Common in } \\
\text { Children }\end{array}$ & $33 \%$ & {$[4]$} \\
\hline CLL & $\begin{array}{l}\text { Lymphoid } \\
\text { B or T cell }\end{array}$ & $\begin{array}{l}\text { Chromosomal } \\
\text { abnormalities }\end{array}$ & $\begin{array}{l}\text { Swelling of lymph } \\
\text { nodes, spleen } \\
\text { increase }\end{array}$ & $\begin{array}{l}\text { Commonly } \\
\text { effect over } \\
55 \text { age }\end{array}$ & $30 \%$ & [5] \\
\hline
\end{tabular}


3875 people in which 2358 were males and 1517 females. The overall percentage of leukemia in Australia is $2.9 \%$ and estimated number of deaths due to leukemia is $3.9 \%$. Likewise, studies have shown that in Europe 9534 cases were diagnosed and overall percentage of leukemia is 3\% [15]. In Malaysia, the percentage of AML is $3.8 \%$ more common in Adult males [16]. In Saudi Arabia, total 3825 cases of leukemia were diagnosed and the percentage in males was $5.2 \%$ and in females $4.5 \%$ [17]. In case of South Asian countries especially Pakistan, Cancer prevalence ratio is gradually increasing. In Pakistan, between 2010-2012, data reported in Lahore indicated that about 15,840 patients were diagnosed with cancer including 43\% males and 57\% females [18]. In Liaquat National Hospital, cross sectional study conducted from 2011 to 2014 showed that 89 patients with CCL were recruited in which $69.7 \%$ were males and $30.3 \%$ were females; with age ranging between 35 - 80 years. In 2012, population of Pakistan is estimated to be 179.9 million out of which 148,000 people were diagnosed with cancer per year and before age of 75 ; risk of getting disease was $11.8 \%$ with 101,000 people dying from cancer per year.

Different treatments options are available to target leukemia. These included chemotherapy, bone marrow transplant and radiotherapy. In AML, FF-10501-01; a novel inosine-5'-monophosphate dehydrogenase inhibitor, reduce cell proliferation and causes cell death in leukemia tumors because it has strong anti-leukemic effect targeting at the guanine nucleotide biosynthesis regardless of HMA resistance [19]. Rituximab is a high affinity chimeric mouse anti-CD20 monoclonal antibody which is currently used for the treatment of non-Hodgkin's lymphoma (NHL), CLL and autoimmune disorders. It is used as a single agent and in combination with chemotherapy, particularly with fludarabine or fludarabine and cyclophosphamide (R-FC regimen) [20]. The modern approaches used to the treat CML focus on chronic phase (CP) CML, including both TKI-based therapies such as imatinib, dasatinib, nilotinib, bosutinib and ponatinib, and non-TKI medications, such as omacetaxine [21]. Recent advances in nanotechnology have enabled the treatment of leukemia using nanoparticles. It has long term effects and it has direct effect on chemotherapy. It improves the bioavailability or therapeutic efficiency of anti-cancer agents. Therefore, new therapeutic approaches reduce the toxicities and nanoparticles are combined with high density lipoprotein-based drug delivery system to examine their potential role in the enhanced treatment of leukemia in children [22].

Despite advanced in the treatment options available for leukemia, there is need for novel therapeutic strategies for treatment of leukemia patients. In ALL, corticosteroids are specifically used for treatment of leukemia in childhood. Corticosteroids have adverse effect on patients of leukemia in the form of neurophysiological effects [23]. Chemotherapy or radiotherapy put adverse effects on human which induce serious problems like liver damage, nerve damage, heart disorders, loss of immunity and also cause a second type of cancer. Chemotherapy has unwanted side effects such as hair loss, loss of appetite, mouth sores, diarrhea, nausea and vomiting, lowering the blood cells because chemotherapy affects 
abnormal cells as well as normal cells.

Meanwhile, several strategies employ natural compounds for treatment of leukemia. Leukemia can be treated by turmeric curcuminoid, also called diferuloyl methane. It is found in rhizome of Curcuma longa which has very strong anticancer properties. Curcumin has been attractive for many generations, not only in cooking dishes but also with in integral medicine [24]. In 1900s mid, curcumin was declared as biologically active compound, have antibacterial activity, therefore efficient against Salmonella paratyphi, Staphylococcus aureus, Staphylococcus aureus, and Mycobacterium tuberculosis [25] [26]. Curcumin has been used against heath conditioning diseases like stomach disorder, respiratory problems, arthritis, acne, to heal wounds, mitigate insect bites and have anti-inflamatory, anti-diabetic, cholesterol lowering and antioxidant properties [27]. After clinical research FDA confirmed that curcumin efficacious and safe [28]. Various curcumin nutraceutical products use to control the gene expression at molecular level and control cancerous cell proliferation. Recently turmeric gained more attention in scientific literature and research for the treatment of cancer. Scientific literature demonstrates that curcumin has anti-carcinogenic, anti-platelet aggregation and chemopreventive property [29].

The most extensively research of turmeric is, its therapeutic effect and role in cancer obstruction [30]. The curcumin is not only helpful in combination with chemotherapy but is also recommended for chemoprevention [31]. Curcumin acts as natural potential which induce apoptosis in cancer cells as leukemia cell. It caused down regulation of NF-kB or suppress NF-kB gene. We find out from the study of literature that curcumin plays roles as an anticancer agent which work through different mechanisms. It acts as a chemotherapeutic agent as impact on drug induced apoptosis. So it is revealed that curcumin regulate multiple signaling pathway and induce apoptosis in tumor cells and play role in both prevention and treatment of cancer.

\section{Curcumin and Treatment of Leukemia}

Since last two decades, many dietary products and natural compounds are being utilized to treat leukemia. Curcumin is a phenolic compound in nature anti-tumor and anti-inflammatory compound which contain demethoxycurcumin and bis-demethoxy curcumin [32]. It suppressed the uncontrolled growth of cells. It reduces the tumor load and induces apoptosis in cancerous cells. Recent studies investigating its effect on cell culture show that it control cellular proliferation by inducing apoptosis and cell cycle arrest in different types of cancer cell lines by regulating the activity of different tumor suppression genes and oncogenes or by blocking the metalloproteinases matrix [33].

Curcuminoid exert cell apoptosis in leukemic cells having strong anti-inflammatory, antiproliferative and antiangiogenic activity in different types of leukemia at the same time [33]. It has been shown that curcuminoid treatment is cytotoxic at low concentration to HL-60, K562, and U937 cell lines [35]. 
It is potential inhibitor of the different types of cancer at various stages of cancer proliferation and also scavenges free radicals [36] [37]. Moreover, curcumin down regulate the WT1 gene expression and caused apoptosis in Molt4 and K562 cell lines. Recent studies have revealed that pure curcuminoid has cytotoxic effects on cell proliferation, FLT3 expression, inhibition of cell cycle in FLT3 overexpressing stage of eosinophilic leukemic cell line (Eol-1), and prevention of $\mathrm{NF}-\mathrm{kB}$ activation. It also regulates histone acetyltransferase (HAT) and histone deacetylase (HDAC) and DNA methyltransferase 1 enzyme activities. FLT3 transduce signal networks along with MAP kinase, phosphatidylinositol 3-kinase (PI3K), and Jak-STAT pathways. When these pathways are boosted, they become critical for leukemic blasts proliferation or cell growth [38]. Curcumin decreased the nitrogen oxide (NO) synthesis which is involved in leukemia tumor malignancy.

A study involving patients who were given turmeric powder with imatinib for six weeks showed dramatic decrease in nitrogen oxides (NOx) levels. NOx levels in serum were much higher than control. It indicates that curcumin act as adjuvant to decrease the level of NO and played key role in the treatment of CML. Inducible NO synthase (iNOS) has been found to be involved in development of cancer and vitreoretinal disorders. Different studies have reported that curcumin down regulate the expression of iNOS. NOx is associated with the initiation of tumor progression and metastasis. It has been observed that combination of turmeric with imatinib therapy show effective response in the reduction of NO level in serum and minimizing side effects. This study also indicates that NOx levels can be utilized as an indicator of CML and curcumin can be employed as adjuvant to imatinib therapy [39].

\section{Curcumin as Tumor Suppressor and It's Mechanism of Action}

In cancer therapy, phytochemicals either regulate signaling pathways of cell cycle or directly alter the regulatory molecules of the cell cycle. Most of the malignancies of human cancers arise from mutations in the DNA that directly disrupt the function of cell cycle proteins such as cyclin along with tumor suppressor genes; for instance P53 [40]. In recent years, curcumin has gained attention as non-toxic chemotherapeutic agent for the treatment of various types of cancer such as leukemia, lymphoma and multiple myeloma. Curcumin has anti-metastasis, antiproliferative, and proapoptotic effects on cancerous cells including progenitor cells through regulation of molecular mechanisms. It affects various major cellular signaling cascades including Notch-1, TRAIL, signal transducers and activators of transcription, NF- $\kappa \mathrm{B}$, JAK/STAT, PI3K/Akt, and JNK [41]. Curcumin as a single agent has been used to treat various types of cancer because it is safe and protects normal cells by the up-regulation of Nrf2 and products of other antioxidant genes [42].

Different pathways of oncogenes that are blocked by curcumin have been shown 
to inhibit the epidermal growth factor receptor (EGFR), ERBB2, Wnt/ $\beta$-catenin and sonic hedgehog (SHH)/GLIs and down-signaling molecules for instance Akt, NF- $\kappa \mathrm{B}$ and signal transducer and activator of transcription (STATs). Curcumin hits at targeted site and block the expression of different tumor inducing pathways such as AKT, STAT, NP- $\kappa$ B, MAPK, and ROS pathway. It activates caspase pathway which arrest cell cycle at G0/G1, G1/S or G2/M phase and reduce the leukemic load via apoptosis (Figure 1).

\subsection{AKT Pathway}

AKT is a downstream serine/threonine kinase in the RTK/PTEN/PI3K pathway. The activated AKT and phospho-AKT levels are elevated in the majority of glioblastoma cell lines and tumor samples, therefore inhibitors of the Akt pathway represent a potential treatment option against glioblastoma [33]. Molecular insight of AKT kinase protein represents a probable doxorubicin based approach

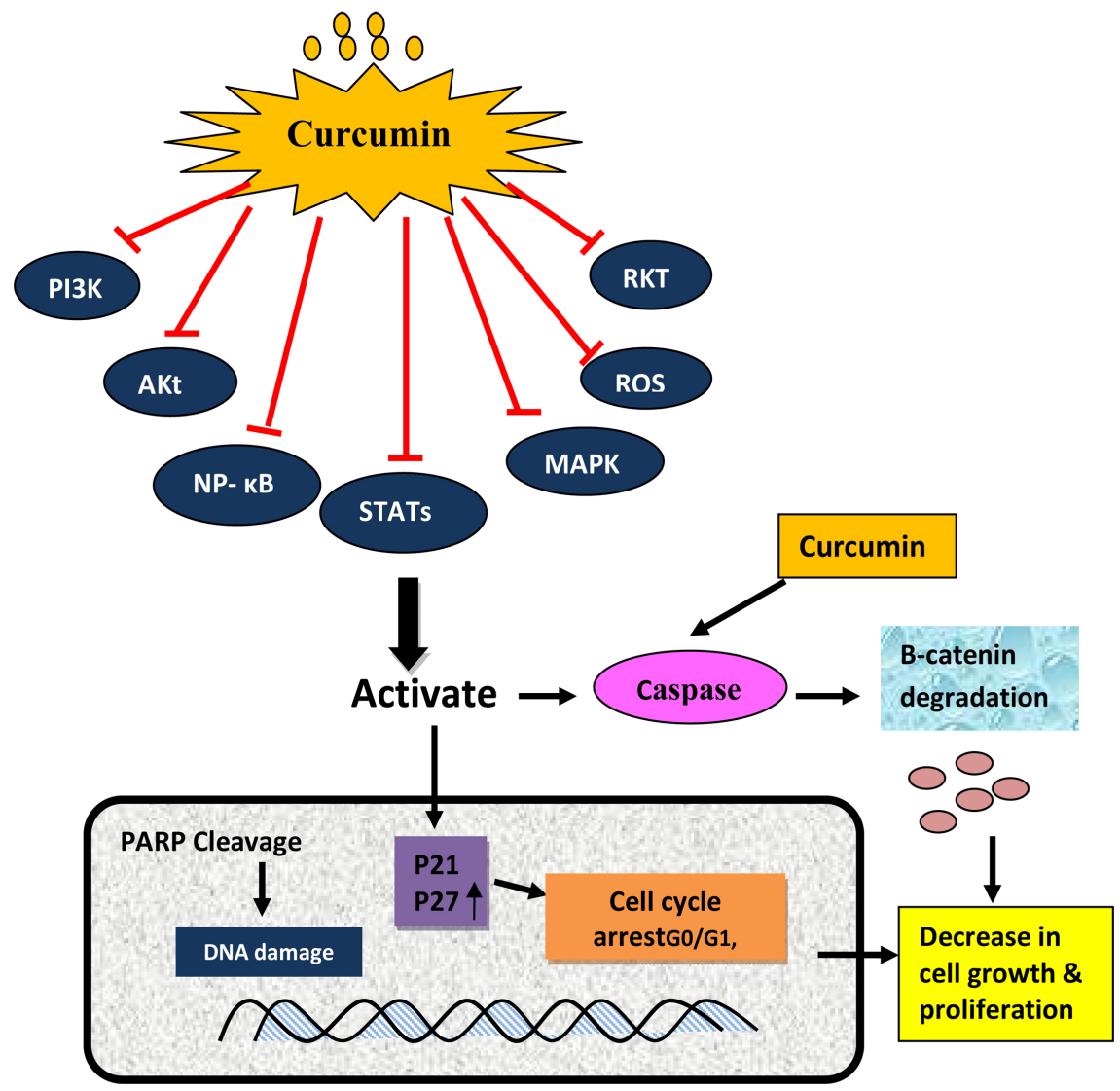

Figure 1. Curcumin as tumor suppressor and it's mechanism of action. Figure 1 illustrates tumor cascade pathways initiated by various growth factors in cancerous cells and anti-Tumorigenic effects stimulate by curcumin on signal transducing elements. Curcumin in conjugated form target at infected site and down-regulate the expression of PI3K, AKt, NP- $\kappa$ B, MAPK, MAPK, and ROS tumor inducing pathways. Further inhibit the expression of p21 and p27 cyclin-dependent kinase inhibitors and mitotic effects inhibit by curcumin as a result cycle arrest and down-regulate the expression of various gene products which involved in the cell growth, proliferation and expand of cancer. 
in inhibiting miR-21 based cancer cell proliferation [43]. Curcumin activates p53, inhibit $\mathrm{AKT}$ gene and block PI3K. It also up-regulate the $\mathrm{Bcl}$ and bax gene which leads apoptosis and stop cell proliferation is presented in (Figure 2). Many oncoproteins and tumor suppressors implicated in cell signaling/metabolic regulation included within the AKT signal transduction pathway in an equilibrium that is altered in many human cancers due to disruption of the structure of these proteins [44].

\subsection{ROS Pathway}

ROS act in multiple signaling pathways related to different behaviors in tumor

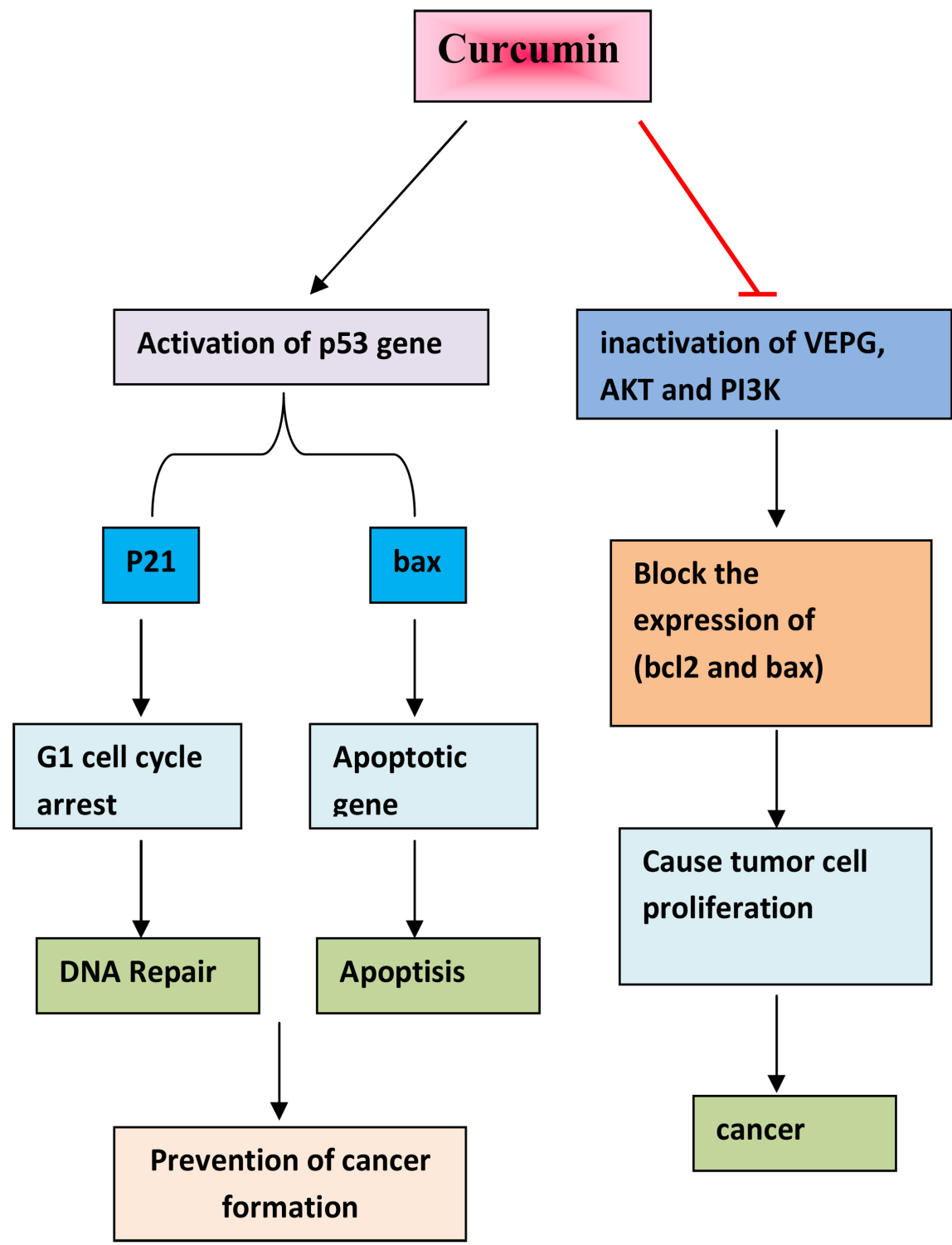

Figure 2. How curcumin regulate AKT pathway? Figure 2 is Schematic illustration of blockage of Akt gene and activation of p53 tumor suppressive gene. Curcumin inactivate VEPG, AKT and PI3K gene directly and activate p53 gene which repairs DNA and bcl2 and bax gene induce apoptosis in tumor cells and prevent cancer proliferation. 
cells. ROS are oncogenic linked to carcinogenesis such as initiation, promotion and progression but also used to kill cancerous cell via non-surgical approach [45]. Dietary curcumin elevates intracellular ROS and has potential to remove the mitochondrial membrane of leukemic cells and caused apoptosis [46] [47]. Curcumin induce the ROS production in mitochondria and causes the release of cytochrome $\mathrm{C}$ from inner lining of mitochondria to the cytosol or nucleus and accompanying PARP cleavage. As a result caspase pathway activates and causes apoptosis in tumor cell [48]. Curcumin-induced rapid oxidative stress and release AIF from mitochondria to cytosol and, hence leading to caspase 3-independent apoptosis [49]. ROS stress creates in cells due to abnormality of cancer regulating genes which transferring the normal cells into tumor cells [50]. Curcumin intergraded into the inner lining of mitochondria and conjugated with oxygen species thus prevent ROS production by blocking their transcriptional factor such as TNF- $\alpha$, and NF- $\kappa$ B (Figure 3 ).

E Moreover, the inhibitory effect of curcumin on different genes and proteins such as Bcl-2, VCAM-1, Cyclin D1, Bax, NF- $\kappa \beta$, VGEF or COX-2 has also been reported [51]. The sustained activation of the ROS-ASK1-c-Jun N-terminal kinase pathway may be an important mediator of the synergistic effect of curcumin and ABT-737 [52]. $15 \mu \mathrm{M}$ curcumin attenuated by 55\% the increase in ROS production, by $94 \%$ the reduction of GSH/glutathione disulfide (GSSG) ratio, and by $49 \%$ the cell death induced by hemin [53]. Curcumin dose-dependently reduced the expression of PKC $\alpha$, P47phox, Nox-2 and phosphorylated ATF-2, as well as intracellular ROS generation, suggesting the inhibitory effect of curcumin on the activation of the PKC $\alpha / \mathrm{Nox}-2 / \mathrm{ROS} / \mathrm{ATF}-2$ pathway. In conclusion, the $\mathrm{PKC} \alpha /$ Nox-2/ROS/ATF-2/MMP-9 signaling pathway is activated in cancer A549 cells, which could be modulated by curcumin to inhibit cell invasiveness [54].

\subsection{NK-KB Inhibition}

Nuclear factor Kappa beta is constitutively expressed in cancer tissues and stimulates the transcription of various tumor-related genes [55]. Curcumin acts as a NF- $\kappa$ B inhibitor and exhibits both anti-inflammatory and anti-cancer properties. Findings from several studies indicate that EF31 is a more potent inhibitor of NF- $\kappa$ B activity and EF31 represents a promising curcumin analogue for therapeutic treatment [56]. NF- $\kappa$ B transcriptional factor synthesized in cytoplasm, govern signaling pathways associated with cancer and NF- $\kappa \mathrm{B}$ targets growth cells, cytokines, and inflammatory molecules [57]. NF- $\kappa$ B make a structural complex with I- $\kappa$ B inhibitor and phosphorylated NF- $\kappa$ B after which p-NF- $\kappa$ B translocate in the nucleus to transcribe apoptosis activating genes. Treatment with curcumin block $\mathrm{I} \kappa \mathrm{Bs}$-inhibitors leading to phosphorylation and inhibition of NF- $\kappa$ B-regulated gene and gene products (MMP-3, MMP-9, growth factors, Bcl-2, Bcl-xL, and TNF- $\alpha$ ) ultimately leading blockage of translocation of NF- $\kappa$ B and loss in its ability to bind with DNA [58] [59] as shown in Figure 4. Curcumin block the entry of NF- $\kappa \mathrm{B}$ into nucleus by down regulating the expression 


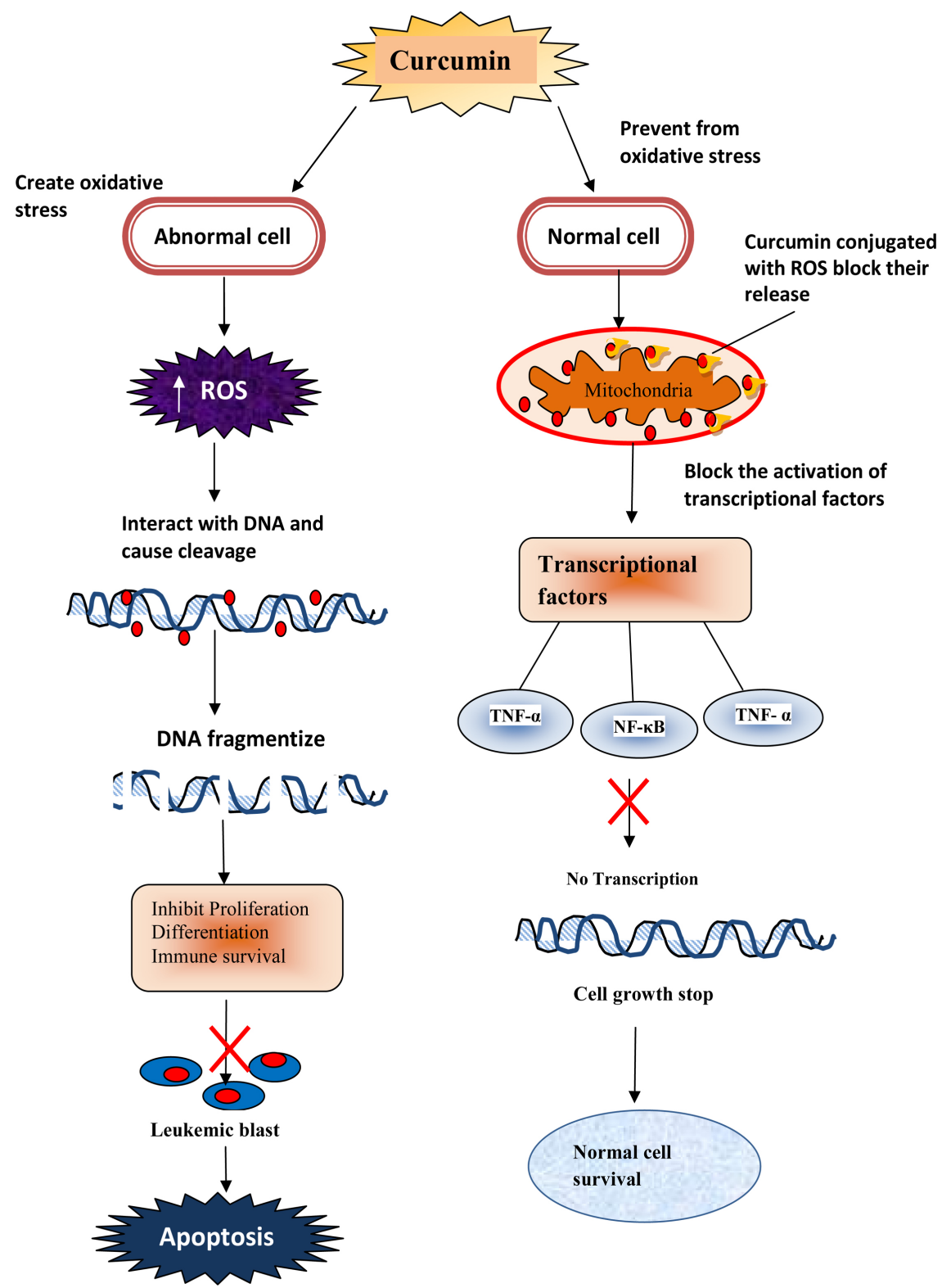

Figure 3. How curcumin block ROS production. Figure 3: Schematic representation shows the dual activity of curcumin it increases the ROS generation in abnormal or leukemic cells which creates stress and causes the cleavage of DNA as a result cancerous cell death via apoptosis. In normal cells it block the ROS block the production of ROS, also block the transcriptional factor TNF- $\alpha$, and NF- $\kappa$ B which involve in the proliferation of leukemic blast, as a result normal cell survive.

of regulatory proteins of cell cycle and Bcl-2 survival factor [60]. Curcumin block oncogenes expression including Akt, CDKs, MAPKs, ERK, myc, NIK and also inhibit NF- $\kappa$ B-regulated gene products induced by TNF, as c-myc, COX-2, cyclin D1 and Bcl-2, Bcl-x(L), COX-2, matrix metalloproteinase-9, cyclin D1, adhesion molecule [61]. Long term use of curcumin may contribute in cancer suppression or weaken its progression via inhibition of IL- 6 and TNF- $\alpha$ through nuclear factor NF- $\kappa$ B and ETS protein [62]. 
NF-kB Inhibition

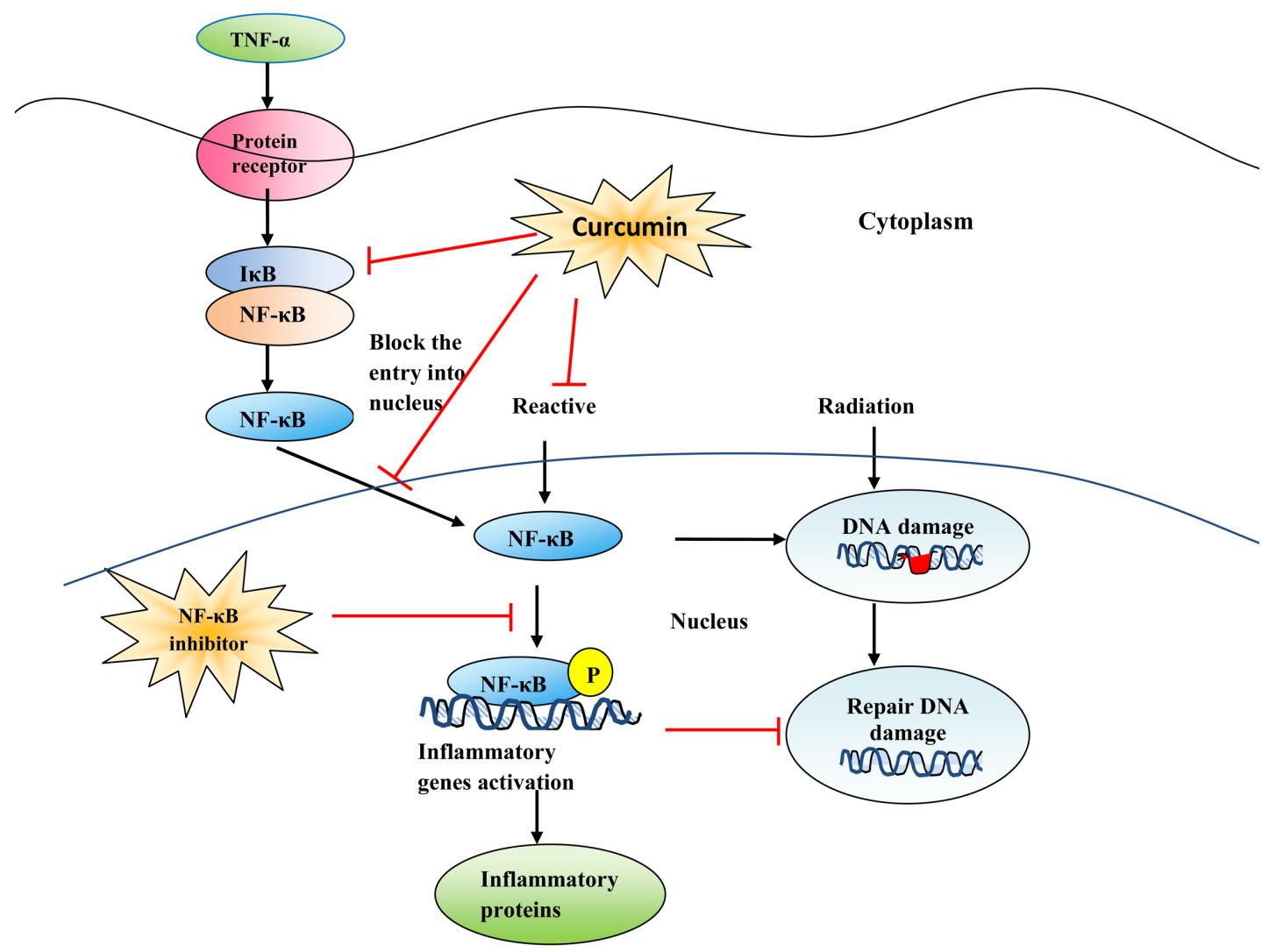

Figure 4. NF- $\kappa \mathrm{B}$ inhibition by curcumin. Figure 4: Curcumin prevents the entry of NF- $\kappa$ B into nucleus by down regulating the expression of regulatory proteins of cell cycle. Curcumin block $\mathrm{I} \kappa \mathrm{Bs}$, inhibits phosphorylation and blocs NF- $\kappa$ B regulated gene and gene products and also weaken the NF- $\kappa$ B DNA binding ability. As a result, it blocks the production of inflammatory proteins.

\subsection{Curcumin and FLT3 Gene}

There is a high level of expression of FLT3 gene in leukemic patients. FLT3 gene is a member of the type III receptor tyrosine kinase. Abnormal tyrosine kinase receptors are present in endoplasmic reticulum [63]. FLT3 gene is most commonly overexpressed in AML. AML mutated with FLT3 gene affects about 30\% of adult patients [63]. Binding of FLT3 with its ligand stimulate differentiation of cancerous cells [64]. FLT3 gene stimulates phosphatidylinositol-3-kinase (PI3K), MAP kinase, and Jak-STAT pathways. Stimulation of all these pathways stimulates the uncontrolled differentiation of leukemic cells. Curcumin have inhibiting effects on it, FLT3 interruption, and development of cell cycle (Figure 5). Curcumin loaded miceslle formation has been used to inhibit formation cancerous cells [57]. Many FLT3 inhibitors such as PKC412, AC220, CEP-701, and AR200 have been used to overcome the levels of phosphorylated FLT3 protein. Significant decline was detected in cellular level of FLT3 protein after curcuminoid treatment as it arrested the activity of cell cycle at the G0/G1 phase and decreased the FLT3 and STAT protein levels [65]. Effects of curcumin on different 


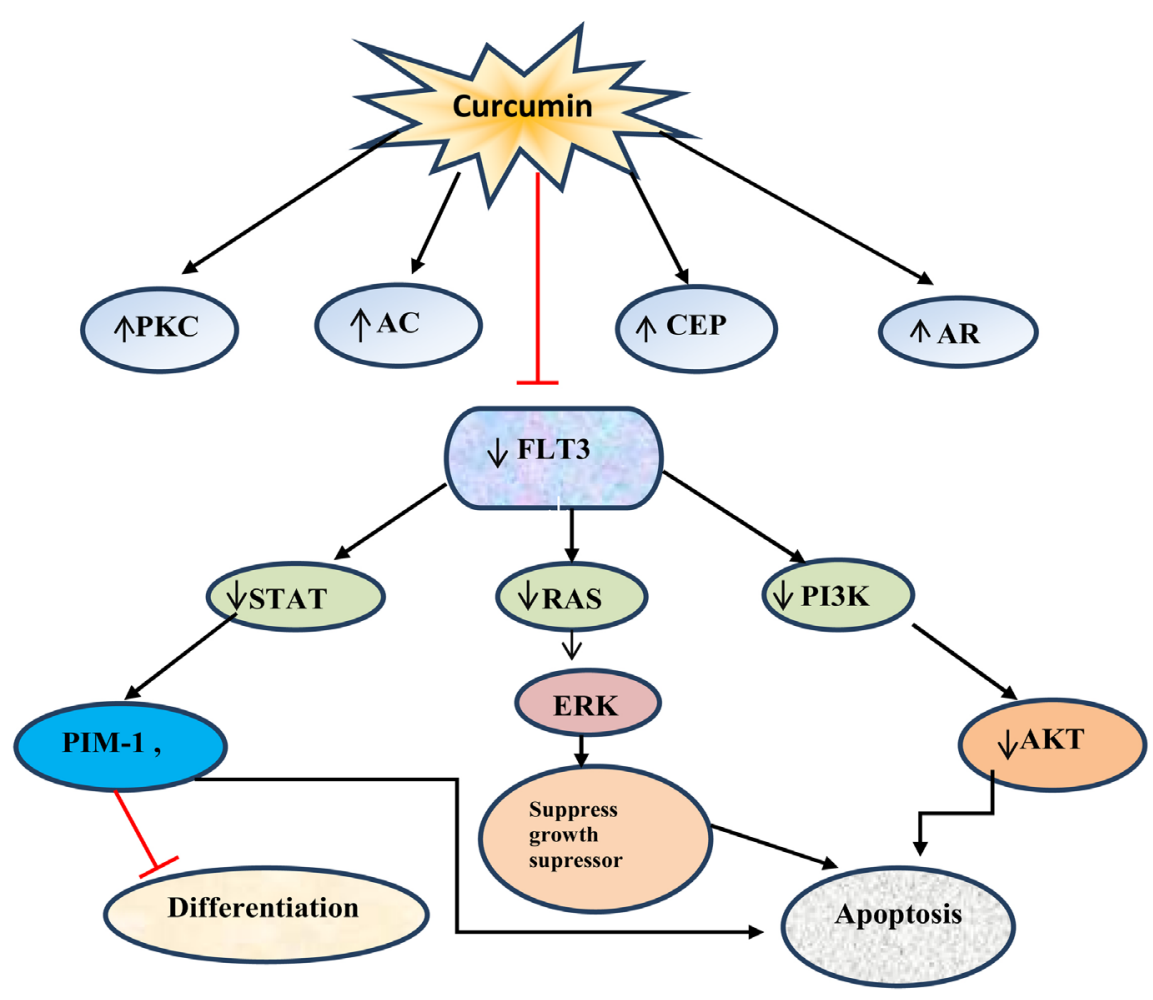

Figure 5. Inhibitory effect of curcumin on FLT3. Figure 5: Curcumin blocks the expression of FLT3 gene, which further inhibits the RAS, STAT, AKT and ERK pathway and stop the growth promotion and causes apoptosis of abnormal cells.

oncogenic pathways are discussed in the Table 2.

\subsection{Dosage of Curcumin}

Humans can tolerate high dosage of curcumin. It has been observed in phase 1 trails curcumin dosage up to 3600 - $8000 \mathrm{mg}$ per day for 4 months didn't had toxic effects except mild diarrhea and nausea which can be controlled easily [66]. Smokers should be take preventive measures while taking curcumin because it can induce ROS production [67]. Curcumin bioavailability can be increased by its modification using nanocarriers such as liposomes and different encapsulation method. Using intravenous infusion, its bioavailability can be increased [68]. There are many bio-enhancers such as piperine or silibinin that increases the cellular uptake of curcumin and also help bind it with different polymers [26]. Preparation and compositions of curcumin was difficult, with the development of new analogues or formulations it has better bioavailability. It has been noticed oral bioavailability of curcumin is poor in all pharmacokinetic studies it would limit the application of curcumin. Peculiar route of administration will be critical for the future use of curcumin [66]. There are following advantages and disadvantages disused in the following Table 3.

\section{Conclusion}

In this article, we have described curcumin as a potential anticancer substance 
Table 2. Effect of curcumin on different ontogenic pathways.

\begin{tabular}{|c|c|c|c|}
\hline Pathways & Action of curcumin & Effects of curcumin & As a result \\
\hline AKT Pathway & Activation of P53 gene & $\begin{array}{l}\text { Block the expression of } \\
\text { (bcl2 and bax) }\end{array}$ & Repair DNA or apoptosis \\
\hline ROS Pathway & $\begin{array}{l}\text { Curcumin block the production of } \\
\text { reactive oxygen species }\end{array}$ & Block transcriptional genes & $\begin{array}{l}\text { Cause DNA cleavage } \\
\text { and inhibit leukemic blast }\end{array}$ \\
\hline NF-kB Inhibition & $\begin{array}{l}\text { Block the entry of nuclear } \\
\text { factors into nucleus }\end{array}$ & $\begin{array}{l}\text { Inside the nucleus inhibit the } \\
\text { activation of inflammatory genes }\end{array}$ & Block repair of DNA damage \\
\hline ERK Pathway & $\begin{array}{l}\text { Inhibit the phosphorylation of ERK, JNK, } \\
\text { c-Jun JunB pathways and } \\
\text { degradation of caspase-3 }\end{array}$ & $\begin{array}{l}\text { ERK1/2, JNK and downstream } \\
\text { signaling proteins were increased }\end{array}$ & $\begin{array}{l}\text { By the use of high dose it induce } \\
\text { apoptosis in leukemic cells }\end{array}$ \\
\hline FLT3 gene & Block the expression of FLT3 gene & $\begin{array}{l}\text { further inhibit the RAS, STAT, } \\
\text { AKT and ERK pathway }\end{array}$ & $\begin{array}{l}\text { Inhibit growth promotion and } \\
\text { differentiation and cause } \\
\text { apoptosis }\end{array}$ \\
\hline
\end{tabular}

Table 3. Advantages and disadvantages of curcumin.

\begin{tabular}{|c|c|}
\hline Advantages of curcumin & Disadvantages of curcumin \\
\hline $\begin{array}{l}\text { It is useful for leukemia treatment due to } \\
\text { anti-inflammatory and anti-oxidant properties. }\end{array}$ & $\begin{array}{l}\text { By the use of high dosage of curcumin it affects the stomach and } \\
\text { cause ulcer, vomiting and nausea. }\end{array}$ \\
\hline $\begin{array}{l}\text { Curcumin naturally exist as antioxidant and increase the antioxidant } \\
\text { capability of your body to prevent free radicals production. }\end{array}$ & $\begin{array}{l}\text { In some cases it cause allergic reactions in the body like } \\
\text { shortness of breath, wheezing, rashes, irritation, } \\
\text { burning in urine, hives and chest pain. }\end{array}$ \\
\hline Curcumin inverse the cancer stages. & Avoid in pregnancy. \\
\hline $\begin{array}{l}\text { Curcumin has anti-cancer activity kills cancer cells during apoptosis in } \\
\text { molecular pathways it does not kill normal cells. It prevents cancer } \\
\text { from spreading due to anti-proliferative activity. }\end{array}$ & Avoid in suffering from bleeding disorder. \\
\hline $\begin{array}{l}\text { Curcumin inhibit the expression of NF-kappa B, Bcl-2 and activating } \\
\text { caspase-3 and MAPK signaling. MMP-2 and MMP-9 are involved in } \\
\text { inflammation turmeric also suppress them. }\end{array}$ & Discontinue prior to surgery. \\
\hline $\begin{array}{l}\text { In CLL curcumin inhibit different cancer survival } \\
\text { pathways like STAT3, Akt or NF-kappa. }\end{array}$ & Avoid in suffering from gall bladder obstruction. \\
\hline $\begin{array}{l}\text { In AML curcumin suppress the DNA-Methyltransferase } \\
\qquad 1 \text { and also prevent cancer growth. }\end{array}$ & $\begin{array}{l}\text { It is advised not to take curcumin supplements concomitantly } \\
\text { with any other medicine supplements are unregulated. }\end{array}$ \\
\hline $\begin{array}{l}\text { Curcumin have anti-angiogenic activity. It interferes with pathways } \\
\text { such as protein kinase } \mathrm{C} \text { and transcriptional factors. It also inhibits } \\
\text { pro-angiogenic factors like VEGF and BFGF. }\end{array}$ & Curcumin not easily absorbed in the blood stream. \\
\hline $\begin{array}{l}\text { Curcumin radiosensitized the effect by the } \\
\text { inhibtionofPI3K/Akt-dependent NF-kappa B pathway, } \\
\text { it also enhances the sensitizing the effect of radiotheraphy. }\end{array}$ & Poor absorption. \\
\hline $\begin{array}{l}\text { It can reduce cancer risk if use curcumin in diet, it induce } \\
\text { anti-apoptotic signals and regulate the changes } \\
\text { in DNA to prevent cancer development. }\end{array}$ & More research is needed. \\
\hline
\end{tabular}

that blocks different cancer-regulating pathways inhibiting proliferation of cancerous blood cells, influencing cell cycle, apoptotic and anti-apoptotic signaling. Curcumin has ability to overcome the production of leukemic blast and mod- 
ulate their expression. Curcumin hits at the targeted site and controlled its mechanism of action by blocking the expression of cancerous genes. Studies evaluate the effects of the curcumin spice and confirmed that it is a potential inhibitor of cancer and acts as antioxidant, inhibits the ROS production and induces cell death in leukemic blast. Considering the low cost, therapeutic potential, and pharmacological safety, curcumin is moving rapidly from the kitchen shelf toward the clinic. The results of these studies provide insight for the designing of potential clinical testing of this agent in cancer treatment. More extensively, clinical trials are required to evaluate its potential in the determination of optimal dose, route of administration, disease targets and potential interactions with other drugs.

\section{Conflict of Interest}

The authors declare that they have no conflict of interest.

\section{References}

[1] Busjan, R., et al. (2017) Oral Health Status in Adult Patients with Newly Diagnosed Acute Leukemia. Clinical Oral Investigations, 2017, 1-8.

[2] Licht, J.D. and Sternberg, D.W. (2005) The Molecular Pathology of Acute Myeloid Leukemia. ASH Education Program Book, 2005, 137-142. https://doi.org/10.1182/asheducation-2005.1.137

[3] Kurzrock, R. and Talpaz, M. (1991) The Molecular Pathology of Chronic Myelogenous Leukaemia. British Journal of Haematology, 79, 34-37. https://doi.org/10.1111/j.1365-2141.1991.tb08116.x

[4] McNeer, J.L., et al. (2017) Acute Lymphoblastic Leukemia. In: Cancer in Adolescents and Young Adults, Springer, Berlin, 151-175. https://doi.org/10.1007/978-3-319-33679-4_7

[5] Akintola-Ogunremi, O., et al. (2002) Chronic Lymphocytic Leukemia Presenting with Symptomatic Central Nervous System Involvement. Annals of Hematology, 81, 402-404. https://doi.org/10.1007/s00277-002-0475-2

[6] Gerstung, M., et al. (2017) Precision Oncology for Acute Myeloid Leukemia Using a Knowledge Bank Approach. Nature Genetics, 49, 332-340. https://doi.org/10.1038/ng.3756

[7] Phuoc, V., et al. (2016) Bone and Joint Infections in Acute Myelogenous Leukemia: A Retrospective Review of Patients at Mayo Clinic. Open Forum Infectious Diseases, Oxford University Press, Oxford.

[8] Haguet, H., et al. (2017) Risk of Arterial and Venous Occlusive Events in Chronic Myeloid Leukemia Patients Treated with New Generation BCR-ABL Tyrosine Kinase Inhibitors: A Systematic Review and Meta-Analysis. Expert Opinion on Drug Safety, 16, 5-12. https://doi.org/10.1080/14740338.2017.1261824

[9] Hanlon, K. and Copland, M. (2017) Chronic Myeloid Leukaemia. Medicine, 45, 287-291.

[10] Guest, E.M. and Stam, R.W. (2017) Updates in the Biology and Therapy for Infant Acute Lymphoblastic Leukemia. Current Opinion in Pediatrics, 29, 20-26. https://doi.org/10.1097/MOP.0000000000000437

[11] Glavey, S., et al. (2017) Emergence of Bruton's Tyrosine Kinase-Negative Hodgkin 
Lymphoma during Ibrutinib Treatment of Chronic Lymphocytic Leukaemia. European Journal of Haematology, 99, 378-380. https://doi.org/10.1111/ejh.12911

[12] Goede, V., et al. (2014) Obinutuzumab Plus Chlorambucil in Patients with CLL and Coexisting Conditions. New England Journal of Medicine, 370, 1101-1110. https://doi.org/10.1056/NEJMoa1313984

[13] Khaled, S., Al Malki, M. and Marcucci, G. (2016) Acute Myeloid Leukemia: Biologic, Prognostic, and Therapeutic Insights. Oncology, 30, 318-318.

[14] Siegel, R., et al. (2014) Cancer Statistics, 2014. CA: A Cancer Journal for Clinicians, 64, 9-29. https://doi.org/10.3322/caac. 21208

[15] Socinski, M., et al. (2004) Combined Modality Trials of the Cancer and Leukemia Group B in Stage III Non-Small-Cell Lung Cancer: Analysis of Factors Influencing Survival and Toxicity. Annals of Oncology, 15, 1033-1041. https://doi.org/10.1093/annonc/mdh282

[16] Meng, C.Y., et al. (2013) Cytogenetic Profile of de Novo Acute Myeloid Leukemia Patients in Malaysia. International Journal of Biomedical Science: IJBS, 9, 26-32.

[17] Abu-Elmagd, M., et al. (2015) Individualized Medicine Enabled by Genomics in Saudi Arabia. BMC Medical Genomics, 8, S3. https://doi.org/10.1186/1755-8794-8-S1-S3

[18] Badar, F., et al. (2016) Epidemiology of Cancers in Lahore, Pakistan, 2010-2012: A Cross-Sectional Study. BMJ Open, 6, e011828.

https://doi.org/10.1136/bmjopen-2016-011828

[19] Yang, H., et al. (2017) Preclinical Activity of FF-10501-01, a Novel Inosine-5-monophosphate Dehydrogenase Inhibitor, in Acute Myeloid Leukemia. Leukemia Research, 59, 85-92. https://doi.org/10.1016/j.leukres.2017.05.016

[20] Robak, T. (2012) Rituximab for Chronic Lymphocytic Leukemia. Expert Opinion on Biological Therapy, 12, 503-515. https://doi.org/10.1517/14712598.2012.665444

[21] Pasic, I. and Lipton, J.H. (2017) Current Approach to the Treatment of Chronic Myeloid Leukaemia. Leukemia Research, 55, 65-78.

https://doi.org/10.1016/j.leukres.2017.01.005

[22] Basha, R., et al. (2014) Targeted Nanoparticles for Pediatric Leukemia Therapy. Frontiers in Oncology, 4, 101. https://doi.org/10.3389/fonc.2014.00101

[23] Pépin, A., et al. (2016) Adverse Neuropsychological Effects Associated with Cumulative Doses of Corticosteroids to Treat Childhood Acute Lymphoblastic Leukemia: A Literature Review. Critical Reviews in Oncology/ Hematology, 107, 138-148. https://doi.org/10.1016/j.critrevonc.2016.09.001

[24] Gupta, S.C., et al. (2012) Discovery of Curcumin, a Component of Golden Spice, and Its Miraculous Biological Activities. Clinical and Experimental Pharmacology and Physiology, 39, 283-299. https://doi.org/10.1111/j.1440-1681.2011.05648.x

[25] Gibson-Moore, H. and Spiro, A. (2017) Can Turmeric Really Prevent Cancer? Nutrition Bulletin, 42, 141-147. https://doi.org/10.1111/nbu.12262

[26] Kocaadam, B. and Şanlier, N. (2017) Curcumin, an Active Component of Turmeric (Curcuma longa), and Its Effects on Health. Critical Reviews in Food Science and Nutrition, 57, 2889-2895. https://doi.org/10.1080/10408398.2015.1077195

[27] Shanmugam, M.K., et al. (2015) The Multifaceted Role of Curcumin in Cancer Prevention and Treatment. Molecules, 20, 2728-2769.

https://doi.org/10.3390/molecules20022728

[28] Caka, M., et al. (2017) Controlled Release of Curcumin from Poly (HEMA-MAPA) Membrane. Artificial Cells, Nanomedicine, and Biotechnology, 45, 426-431. 
https://doi.org/10.3109/21691401.2016.1160913

[29] Qadir, M.I., Naqvi, S.T.Q. and Muhammad, S.A. (2016) Curcumin: A Polyphenol with Molecular Targets for Cancer Control. Asian Pacific Journal of Cancer Prevention, 17, 2735-2739.

[30] Kasi, P.D., et al. (2016) Molecular Targets of Curcumin for Cancer Therapy: An Updated Review. Tumor Biology, 37, 13017-13028. https://doi.org/10.1007/s13277-016-5183-y

[31] Kelkel, M., et al. (2010) Potential of the Dietary Antioxidants Resveratrol and Curcumin in Prevention and Treatment of Hematologic Malignancies. Molecules, 15, 7035-7074. https://doi.org/10.3390/molecules15107035

[32] László Hackler Jr., B.Ó., Gyuris, M., Sipos, P., Fábián, G., Molnár, E., Marton, A., Faragó, N., Mihály, J., Nagy, L.I., Szénási, T., Diron, A., Párducz, Á., Kanizsai, I. and Puskás, L.G. (2016) The Curcumin Analog C-150, Influencing NF- $\kappa$ B, UPR and Akt/Notch Pathways Has Potent Anticancer Activity in Vitro and in Vivo. PLoS ONE, 11, e0149832.

[33] Wilken, R., Veena, M.S., Wang, M.B. and Srivatsan, E.S. (2011) Curcumin: A Review of Anti-Cancer Properties and Therapeutic Activity in Head and Neck Squamous Cell Carcinoma. Molecular Cancer, 10, 12.

[34] Fresco, P., et al. (2010) The Anticancer Properties of Dietary Polyphenols and Its Relation with Apoptosis. Current Pharmaceutical Design, 16, 114-134. https://doi.org/10.2174/138161210789941856

[35] Anuchapreeda, S., et al. (2006) The Cytotoxic Effect of Curumin, Demethoxycurcumin and Bisdemethoxycurcumin Purified from Turmeric Powder on Leukemic Cell Lines. Journal of Associated Medical Sciences, 39, 60-71.

[36] Aggarwal, B.B. and Sung, B. (2009) Pharmacological Basis for the Role of Curcumin in Chronic Diseases: An Age-Old Spice with Modern Targets. Trends in Pharmacological Sciences, 30, 85-94. https://doi.org/10.1016/j.tips.2008.11.002

[37] Yu, J., et al. (2013) Curcumin Down-Regulates DNA Methyltransferase 1 and Plays an Anti-Leukemic Role in Acute Myeloid Leukemia. PLoS ONE, 8, e55934. https://doi.org/10.1371/journal.pone.0055934

[38] Grafone, T., et al. (2012) An Overview on the Role of FLT3-Tyrosine Kinase Receptor in Acute Myeloid Leukemia: Biology and Treatment. Oncology Reviews, 6, e8. https://doi.org/10.4081/oncol.2012.e8

[39] Ghalaut, V.S., et al. (2012) Effect of Imatinib Therapy with and without Turmeric Powder on Nitric Oxide Levels in Chronic Myeloid Leukemia. Journal of Oncology Pharmacy Practice, 18, 186-190. https://doi.org/10.1177/1078155211416530

[40] Sa, G. and Das, T. (2008) Anti Cancer Effects of Curcumin: Cycle of Life and Death. Cell Division, 3, 14. https://doi.org/10.1186/1747-1028-3-14

[41] Chen, J., Wang, F.-L. and Chen, W.-D. (2014) Modulation of Apoptosis-Related Cell Signalling Pathways by Curcumin as a Strategy to Inhibit Tumor Progression. Molecular Biology Reports, 41, 4583-4594. https://doi.org/10.1007/s11033-014-3329-9

[42] Aggarwal, B.B. (2010) Targeting Inflammation-Induced Obesity and Metabolic Diseases by Curcumin and Other Nutraceuticals. Annual Review of Nutrition, 30, 173-199. https://doi.org/10.1146/annurev.nutr.012809.104755

[43] Ambuj Kumar, V.R., Sethumadhavan, R. and Purohit, R. (2013) AKT Kinase Pathway: A Leading Target in Cancer Research. The Scientific World Journal, 2013, Article ID: 756134. 
[44] Altomare, D.A. and Testa, J.R. (2005) Perturbations of the AKT Signaling Pathway in Human Cancer. Oncogene, 24, 7455-7464.

[45] Wang, J. and Yi, J. (2008) Cancer Cell Killing via ROS: To Increase or Decrease, That Is the Question. Cancer Biology \& Therapy, 7, 1875-1884. https://doi.org/10.4161/cbt.7.12.7067

[46] Gopal, P.K., Paul, M. and Paul, S. (2014) Curcumin Induces Caspase Mediated Apoptosis in JURKAT Cells by Disrupting the Redox Balance. Asian Pacific Journal of Cancer Prevention, 15, 93-100. https://doi.org/10.7314/APJCP.2014.15.1.93

[47] Guo, Y., et al. (2014) Curcumin Induces Apoptosis via Simultaneously Targeting AKT/mTOR and RAF/MEK/ERK Survival Signaling Pathways in Human Leukemia THP-1 Cells. Die Pharmazie-An International Journal of Pharmaceutical Sciences, 69, 229-233.

[48] Thayyullathil, F., et al. (2008) Rapid Reactive Oxygen Species (ROS) Generation Induced by Curcumin Leads to Caspase-Dependent and -Independent Apoptosis in L929 Cells. Free Radical Biology and Medicine, 45, 1403-1412. https://doi.org/10.1016/j.freeradbiomed.2008.08.014

[49] Hail Jr., N. (2008) Mitochondrial Reactive Oxygen Species Affect Sensitivity to Curcumin-Induced Apoptosis. Free Radical Biology and Medicine, 44, 1382-1393.

[50] Zhou, D., Shao, L. and Spitz, D.R. (2014) Reactive Oxygen Species in Normal and Tumor Stem Cells. Advances in Cancer Research, 122, 1-67. https://doi.org/10.1016/B978-0-12-420117-0.00001-3

[51] Pulido-Moran, M., Moreno-Fernandez, J. and Ramirez-Tortosa, C. (2016) Curcumin and Health. Molecules, 21, 264.

[52] Zheng, R., You, Z., Jia, J., Lin, S., Han, S., Liu, A., Long, H. and Wang, S. (2016) Curcumin Enhances the Antitumor Effect of ABT-737 via Activation of the ROS-ASK1-JNK Pathway in Hepatocellular Carcinoma Cells. Molecular Medicine Reports, 13, 1570-1576.

[53] Susana González-Reyes, S.G.-B., Medina-Campos, O.N. and Pedraza-Chaverri, J. (2013) Curcumin Pretreatment Induces Nrf2 and an Antioxidant Response and Prevents Hemin-Induced Toxicity in Primary Cultures of Cerebellar Granule Neurons of Rats. Oxidative Medicine and Cellular Longevity, 2013, Article ID: 801418.

[54] Fan, Z., Duan, X., Cai, H., Wang, L., Li, M., Qu, J., Li, W., Wang, Y. and Wang, J. (2015) Curcumin Inhibits the Invasion of Lung Cancer Cells by Modulating the PKC $\alpha /$ Nox-2/ROS/ATF-2/MMP-9 Signaling Pathway. Oncology Reports, 34, 691-698.

[55] Zheng, J., K.C., Yang, X., Cui, X., Lin, X. and Zhang, Z. (2017) Protein Kinase C- $\alpha$ $(\mathrm{PKC} \alpha)$ Modulates Cell Apoptosis by Stimulating Nuclear Translocation of NF-Kappa-B p65 in Urothelial Cell Carcinoma of the Bladder. BMC Cancer, 17, 432.

[56] Olivera, A., Moore, T.W., Hu, F., Brown, A.P., Sun, A., Liotta, D.C., Snyder, J.P., Yoon, Y., Shim, H., Marcus, A.I., Miller, A.H. and Pace, T.W. (2012) Inhibition of the NF- $\kappa \mathrm{B}$ Signaling Pathway by the Curcumin Analog, 3,5-Bis(2-pyridinylmethylidene)-4-piperidone (EF31): Anti-Inflammatory and Anti-Cancer Properties. International Immunopharmacology, 12, 368-377.

[57] Aggarwal, B.B., Surh, Y.-J. and Shishodia, S. (2007) The Molecular Targets and Therapeutic Uses of Curcumin in Health and Disease. Vol. 595, Springer Science \& Business Media, Berlin. https://doi.org/10.1007/978-0-387-46401-5_1

[58] Kumar, G., et al. (2016) Molecular Mechanisms Underlying Chemopreventive Potential of Curcumin: Current Challenges and Future Perspectives. Life Sciences, 
148, 313-328. https://doi.org/10.1016/j.lfs.2016.02.022

[59] Tuorkey, M. (2014) Curcumin a Potent Cancer Preventive Agent: Mechanisms of Cancer Cell Killing. Interventional Medicine and Applied Science, 6, 139-146. https://doi.org/10.1556/IMAS.6.2014.4.1

[60] Kuttan, G., et al. (2007) Antitumor, Anti-Invasion, and Antimetastatic Effects of Curcumin. In: Aggarwal, B.B., Surh, Y.-J. and Shishodia, S., Eds., The Molecular Targets and Therapeutic Uses of Curcumin in Health and Disease, Springer, Berlin, 173-184.

[61] Aggarwal, S., et al. (2006) Curcumin (Diferuloylmethane) Down-Regulates Expression of Cell Proliferation and Antiapoptotic and Metastatic Gene Products through Suppression of $\mathrm{I} \kappa \mathrm{B} \alpha$ Kinase and Akt Activation. Molecular Pharmacology, 69, 195-206.

[62] Das, L. and Vinayak, M. (2014) Long-Term Effect of Curcumin Down-Regulates Expression of Tumor Necrosis Factor- $\alpha$ and Interleukin- 6 via Modulation of E26 Transformation-Specific Protein and Nuclear Factor- $\kappa \mathrm{B}$ Transcription Factors in Livers of Lymphoma Bearing Mice. Leukemia \& Lymphoma, 55, 2627-2636. https://doi.org/10.3109/10428194.2014.889824

[63] Tima, S., et al. (2017) Stable Curcumin-Loaded Polymeric Micellar Formulation for Enhancing Cellular Uptake and Cytotoxicity to FLT3 Overexpressing EoL-1 Leukemic Cells. European Journal of Pharmaceutics and Biopharmaceutics, 114, 57-68. https://doi.org/10.1016/j.ejpb.2016.12.032

[64] Metts, J., et al. (2017) Imipramine Blue Sensitively and Selectively Targets FLT3-ITD Positive Acute Myeloid Leukemia Cells. Scientific Reports, 7, Article No. 4447.

[65] Tima, S., et al. (2016) Development and Characterization of FLT3-Specific Curcumin-Loaded Polymeric Micelles as a Drug Delivery System for Treating FLT3-Overexpressing Leukemic Cells. Journal of Pharmaceutical Sciences, 105, 3645-3657. https://doi.org/10.1016/j.xphs.2016.09.010

[66] Hsu, C.-H. and Cheng, A.-L. (2007) Clinical Studies with Curcumin. In: The Molecular Targets and Therapeutic Uses of Curcumin in Health and Disease, Springer, Berlin, 471-480. https://doi.org/10.1007/978-0-387-46401-5_21

[67] Shanbhag, V.K.L. (2017) Curcumin in Chronic Lymphocytic Leukemia-A Review. Asian Pacific Journal of Tropical Biomedicine, 7, 549-554. https://doi.org/10.1016/j.apjtb.2017.05.003

[68] Pulido-Moran, M., et al. (2016) Curcumin and Health. Molecules, 21, 264. https://doi.org/10.3390/molecules21030264 


\section{Abbreviations}

ROS: reactive oxygen species

NF- $\kappa$ B: nuclear factor kappa-light-chain-enhancer of activated B cells

Nrf2: basic leucine zipper (bZIP) protein

JAK/STAT: Janus Kinase/Signal Transducer and Activator of Transcription

JNK: c-Jun N-terminal kinase

ALL: acute lymphocytic leukemia

CML: chronic myeloid leukemia

CLL: chronic lymphocytic leukemia

AML: acute myeloid leukemia

RAS: family of retrovirus-associated DNA sequences

p53: tumor suppressor protein

BCR: breakpoint cluster region

TP53: tumor protein 53

NHL: non-Hodgkin's lymphoma

HMA: Health Ministries Association

FDA: Food and Drug Administration

EGFR: Epidermal growth factor receptor

SHH: Syndrome of Hyporeninemic Hypoaldosteronism.

MAPK: Mitogen-Activated Protein Kinases

HAT: histone acetyltransferase

HDAC: histone deacetylase

PI3k: phosphatidylinositol 3-kinase

Eol-1: eosinophilic leukemic cell line

NO: nitrogen oxide

VCAM: vascular cell adhesion molecule

GSH: glutathione disulfide hormone

TNF: tumor necrosis factor alpha

ETS: Environmental Tobacco Smoke Oncology

NF- $\kappa$ BTF: Nuclear factor Kappa B transcriptional factor

NF- $\kappa$ BTGC: Nuclear Factor kappa B targets growth cells

PNF- $\kappa$ B: Phosphorylated Nuclear Factor kappa-B 